\title{
Interculturalidad y Masculinidades
}

\section{Interculturality and Masculinities}

\author{
MARÍN-LEVARIO, Carmen†** \& HERNÁNDEZ-NÚÑEZ, Maribel \\ Universidad Intercultural de Chiapas \\ ID 1 ${ }^{\text {er }}$ Autor: Carmen, Marín-Levario / ORC ID: 0000-0001-5253-4037, CVU CONACYT ID: 794262 \\ ID $1^{\text {er }}$ Coautor: Maribel, Hernández-Núñez / ORC ID: 0000-0002-7691-4875
}

DOI: $10.35429 / J T M S .2019 .15 .5 .1 .14$

Recibido 04 de Marzo 2019; Aceptado 30 Junio, 2019

\section{Resumen}

Objetivo: Analizar cómo el grupo juvenil "Nuestra Señora del Carmen”, de Nuevo Carmen Tonapac, en el municipio de Chiapa de Corzo, Chiapas, son portadores del saber musical tradicional perteneciente a la cultura zoque. Metodología: La investigación documental, giró en torno a la Etnomusicología, los Estudios Culturales, la Comunicación Intercultural, los Estudios de Género que, en conjunto, permitieron explicar y sustentar el tema de investigación; asimismo, la aplicación de entrevistas no estructurada y estructurada, las preguntas se hicieron desde la perspectiva de género, para identificar conductas sexistas de estos jóvenes, incluyendo la visión que ellos tienen hacia su sexo masculino y también hacia el sexo femenino, los estereotipos de la comunidad para la construcción identitaria de un hombre y una mujer, y la posible existencia de participación femenil dentro del grupo musical. Contribución: Divulgar el trabajo de los músicos tradicionales porque tienen el don de entender la música del tambor y del carrizo, además de una labor importante en las ceremonias, ritos y fiestas patronales, son encargados de alegrar las festividades.

\section{Identidad, Músicos Tradicionales, Masculinidades}

\begin{abstract}
Objective: Analyze how the "Nuestra Señora del Carmen" youth group, from Nuevo Carmen Tonapac, in the municipality of Chiapa de Corzo, Chiapas, are carriers of traditional musical knowledge belonging to the Zoque culture. Methodology: Documentary research revolved around Ethnomusicology, Cultural Studies, Intercultural Communication, Gender Studies that together, allowed to explain and support the research topic; also, the application of unstructured and structured interviews, questions were asked from the gender perspective, to identify sexist behaviors of these young people, including their vision towards their masculine sex and also towards feminine sex, the stereotypes of the community for the identity construction of a man and a woman, and if they would allow women to participate in their musical group. Contribution: Disseminate the work of traditional musicians because they have the gift of understanding the music of the drum and reed, in addition to an important work in ceremonies, rites and festivities, are responsible for cheering the festivities.
\end{abstract}

Identity, Traditional Musicians, Masculinities

Citación: MARÍN-LEVARIO, Carmen \& HERNÁNDEZ-NÚÑEZ, Maribel. Interculturalidad y Masculinidades. Revista Transdisciplinaria de Estudios Migratorios. 2019, 5-15: 1-14

\footnotetext{
*Correspondencia al Autor (correo electrónico: carmen.levario@unich.edu.mx)

$\dagger$ Investigador contribuyendo como primer Autor.
} 


\section{Introducción}

A lo largo de la historia, los objetos melodiosos en conjunto con las y los intérpretes de músicas tradicionales, también identificadas como originales, provenientes de un determinado territorio han hecho que dicha práctica sea fundamental en seguir reproduciendo las composiciones tradicionales que les dan identidad cultural ante otros grupos sociales en distintos eventos. Los intérpretes de los sonidos se han preocupado por aprender y fomentar el gusto e interés por conservar sus composiciones tradicionales.

La investigación se orientó al conocimiento de la cultura musical zoque interpretada por un grupo juvenil, quienes tienen la preocupación de conservar su música tradicional, llamado "Nuestra Señora del Carmen"; estos intérpretes provocan efectos sonoros generados por pulsaciones musicales creados a través de un tambor, más dos baquetas y una flauta elaborada de carrizo, misma que es otra forma de expresión proveniente de la comunidad Nuevo Carmen Tonapac, municipio de Chiapa de Corzo, Chiapas.

Es importante saber que la noción de músicos tradicionales en esta investigación consideró los aportes de la Etnomusicología con la intención de valorar las melodías provenientes de las comunidades originarias. También se retomaron aportes de los Estudios Culturales a fin de reconocer a los grupos populares. Por supuesto que desde la Comunicación Intercultural en calidad de herramienta de interacción entre una y/o grupos de personas, para el análisis de las identidades, como característica de una o más personas.

Se consideró relevante saber las opiniones, y el sentir de las familias de estos jóvenes intérpretes, debido a las creencias existentes en la comunidad hacia los músicos locales, y es que la gente de Nuevo Carmen Tonapac cree que los músicos tradicionales son brujos o practican algún tipo de magia debido a la habilidad que ellos han desarrollado para tocar el carrizo o el tambor.
La investigación fue de carácter cualitativa y las técnicas de investigación fueron las siguientes: La investigación documental, giró en torno a definir conceptos sobre músicos tradicionales, identidad, migraciones culturales, masculinidades, nociones vistas desde la Etnomusicología, los Estudios Culturales, la Comunicación Intercultural, los Estudios de Género que bajo estas premisas se explica y sustenta el tema de investigación; asimismo, los tipos de entrevistas (no estructurada y estructurada) que ayudaron a esclarecer los supuestos respecto por qué no se integraron al otro grupo de músicos, conocidos entre ellos como "los señores" (mayores) que también existen en la comunidad de estudio; y la actividad cultural de los jóvenes músicos tradicionales de carrizo y tambor como portadores de un saber tradicional de su localidad, interesó recuperar información de manera interactiva sobre su herencia zoque, y de esta forma empezar a vincularse con ellos utilizando el lenguaje castellano para comunicarse y recabar información en calidad de actores principales.

Los músicos tradicionales y la música tradicional son campos que en la actualidad se han estudiado, pero que todavía no se han abarcado en su totalidad, debido a que falta mucho por descubrir acerca de los artistas locales como portadores de los sonidos tradicionales de su entidad, y sobre las melodías originales.

Los músicos tradicionales tienen una labor importante en las ceremonias, ritos y fiestas patronales, porque estas personas son las encargadas de alegrar las festividades; además ellos deben tener el don de entender la música del tambor y del carrizo.

\section{Descripción del problema}

Hay la opinión de cierta parte de la comunidad que influye negativamente en las juventudes para que no se interesen por la música zoque, y es que consideran que dicha labor está asociada con la brujería. Aunado al desinterés por la preservación y las melodías zoques debido a la influencia de géneros musicales anglosajones u occidentales y al fenómeno migratorio de carácter estatal, nacional e internacional, lo que provoca cierta pérdida de los saberes y conocimientos locales y, agudiza el desarraigo por las raíces culturales 
La satisfacción de los músicos tradicionales pertenecientes a la cultura zoque incrementa significativamente el deleite general por ser portadores del saber musical tradicional de Chiapas.

En un primer momento, se expone, Nuevo Carmen Tonapac, el pueblo zoque migrante; se explica la importancia de hacer esta investigación cualitativa en un asentamiento producto de una reubicación ocasionada por la erupción del Volcán Chichonal (28 de marzo 1982); las razones de indagar respecto a cómo es que los jóvenes de descendencia zoque decidieron convertirse en músicos tradicionales $\mathrm{y}$ conformar el grupo juvenil aludido; igualmente se describe la ubicación del asentamiento de estudio. En un segundo momento, se aborda, Música tradicional, Interculturalidad y Masculinidad; se presentan los conceptos, nociones y categorías utilizadas desde referentes teóricos, que contribuyeron a fundamentar el objeto de estudio.

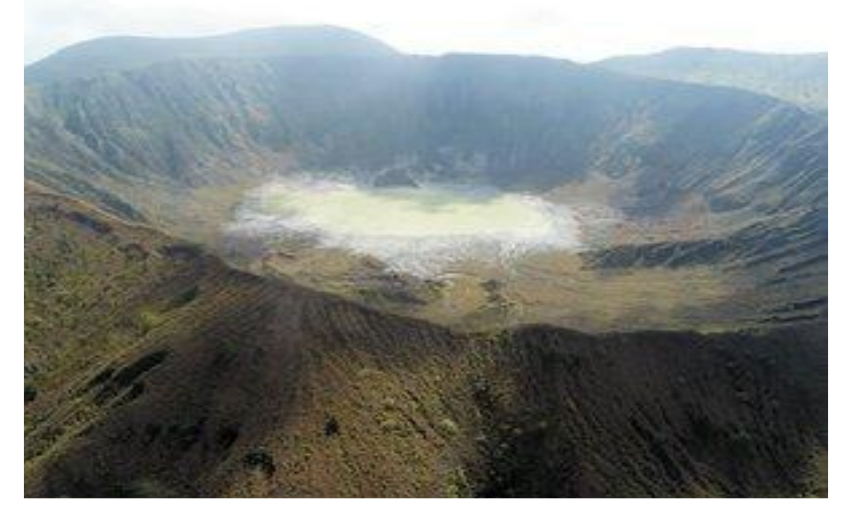

Figura 1 Volcán Chichonal. (s/f)

Foto: Archivo El Universal.

La noción de músicos tradicionales en esta investigación consideró los aportes de la Etnomusicología con la intención de valorar las melodías provenientes de las comunidades originarias. También se retomaron aportes de los Estudios Culturales a fin de reconocer a los grupos populares. Por supuesto que desde la Comunicación Intercultural en calidad de herramienta de interacción entre una y/o grupos de personas, para el análisis de las identidades, como característica de una o más personas. Los estudios de los varones desde una Perspectiva de Género contribuyen a los conocimientos sobre las masculinidades que conciben al sexo biológico masculino como protagonista de los eventos cotidianos y de los rituales artísticos y de sanación en la comunidad.

\section{Nuevo Carmen Tonapac, el pueblo zoque migrante}

El nombre de Tonapac, proviene de la mítica leyenda de un gigante, personaje de la cosmovisión zoque el cual fue castigado por los habitantes al comerse a una joven, su escarmiento fue quemarlo, debido a ese hecho los pobladores nombraron al lugar: To'na (Ceniza) y Pajk (Hueso), y al juntar estas dos palabras resulta To'napajk que quiere decir Ceniza de Hueso.

Mientras que la designación de Nuevo Carmen Tonapac, guarda un significado en cada uno de sus nombres. Nuevo se refiere a la reubicación que tuvieron los habitantes al municipio de Chiapa de Corzo a causa de la erupción del volcán Chichonal, que hizo explosión arrojando piedras, ceniza y lava, provocando destrucción total de Carmen Tonapac del municipio de Chapultenango, sucedida el 28 de marzo de 1982; Carmen por la veneración que le tienen a la Virgen del Carmen, quien es la patrona del pueblo, y Tonapac en recuerdo a la mítica leyenda citada en líneas anteriores.

Coincidencia o no, un anciano del pueblo mencionado en la leyenda que nombró a la comunidad To’napajk, advirtió la desdicha que tendrían las personas que vivían en ese lugar y cerca del volcán, a causa de la Piowa'chuwe (Señora que arde), la dueña del Volcán que hizo explotar su sentir por medio de la erupción del Chichonal (ver figura 1).

Nuevo Carmen Tonapac (ver figura 2) está entre las coordenadas $16^{\circ} 41^{\prime} 44^{\prime \prime}$ N $92^{\circ} 57^{\prime} 21^{\prime \prime} \mathrm{W}$, la localidad se encuentra a una mediana altura de 560 metros sobre el nivel del mar, sus límites son al Norte con la colonia Juan de Grijalva, al Sur con Nucatilí, al Noreste con la colonia Haciendita. El clima predominante es cálido subhúmedo con lluvias en verano, presenta una temperatura media anual de $26^{\circ} \mathrm{C}$ (VIVEMX, 2014). Cuenta con una población total de 1,010 habitantes, dividiéndose en 529 mujeres y 481 hombres. El asentamiento tiene un total aproximado de 207 viviendas. (INEGI, 2010). 


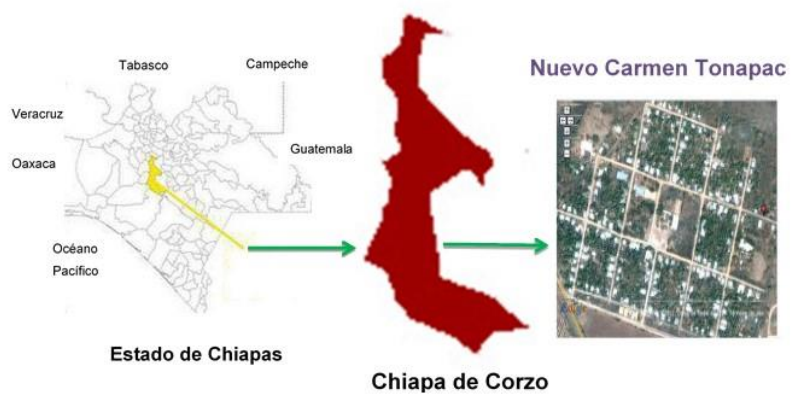

Figura 2 Ubicación geográfica de la Colonia Nuevo Carmen Tonapac en Chiapas

Fuente: Google. (s/f). Mapa de Chiapa de Corzo, Chiapas.

\section{Música tradicional, Interculturalidad y Masculinidad}

En este segundo apartado se presentan diferentes corrientes de autores como son Armand Mattelart y Érik Neveu (2004), Mónica Szurmuk y Robert Mckee Irwim (2009), Juris Tipa (2014), Antonio García de León Griego (2002), Bruno Nettl (1992), Sergio Navarrete (2005), Yolanda Moreno Rivas ((1989), Aurora Oliva (2000), Héctor Vega (2010), Eileen McEntee (1998), Miquel Rodrigo Alsina (2011), Jorge GarcíaVillanueva, Isaura E. López Segura y Jonathan Callejo García (2010), Mario Alberto Reyes (2012). Elsa Guevara Ruiseñor (2008), Michael Kaufman (2000), Santiago (2014), Carlos Bonfil (2011), Vega (2010), Mario Samaniego Sastre (2005), Lawrence Grossberg (2003), Coral Herrera Gómez (2015), Giménez (1996), Ariel García Martínez (2014), Héctor Vega (2010), Jeffrey Weeks (2016), que desde los Estudios Culturales, la etnomusicología, los estudios de la Comunicación Intercultural y las diferentes nociones y variables acerca de los músicos tradicionales de los pueblos originarios de México ayudaron a explicar el concepto clave de este trabajo: músicos tradicionales, en un marco de interculturalidad y de los estudios de la masculinidad.

En el siglo XXI, las culturas que a lo largo de la historia han sido desprestigiadas, consideradas minoritarias, oprimidas, subalternas, rechazadas ya sea por su origen étnico, clase social, distinción sexual, preferencia sexual, etc., o prácticas propias de sus lugares de origen, desde las más cultas hasta la cultura de masas o a la cultura popular, ya no pueden sólo pensarse desde la variable clase social, hoy, se tienen otras variables como la edad, el sexo, el género, las identidades sexuales y de género, las variadas prácticas simbólicas situadas en determinado territorio histórico o geográfico.
En particular a los artistas populares que se han preocupado no sólo por reproducir sus melodías tradicionales sino por conservar sus costumbres y fomentar en su vida cotidiana una práctica cultural, en este caso la musical, para comprender la relación de la cultura con el proceso de construcción de identidades ante la inminente desigualdad social en México.

La música popular de los asentamientos originarios proporciona identidad a la comunidad, debido a que para la gente son considerados elementos de sus usos y costumbres; conservándose con el paso del tiempo, esto gracias a que las nuevas generaciones (niños y jóvenes) reproducen signos (cantos) que dan a entender mensajes, interesándose en seguir fortaleciendo su conocimiento musical.

Ejemplo claro de estas ideas son los músicos tradicionales de la comunidad de Nuevo Carmen Tonapac, que se preocuparon por aprender y conservar los ritmos populares del carrizo y tambor para alabar a una deidad o celebrar un evento, siendo estos jóvenes los elementos que dan identidad a la población, animar las ceremonias, las fiestas, rituales; es una actividad que aluden prácticas culturales o creencias, involucra a los habitantes de la comunidad porque es una actividad de tipo comunitario, manera de transmitir información, conocimientos acerca de sucesos íntimos sobre la localidad, ofrecen mensajes de símbolos musicales que pueden percibir ya sea por recuerdos o sucesos similares que hayan vivido siendo las melodías el medio de llevar los mensajes hacia los pobladores según sus costumbres que representan su lugar de origen ante las demás regiones zoques.

Con la globalización neoliberal y las prácticas occidentales provenientes de otros países, los pueblos originarios utilizan los nuevos hábitos de la cultura de masas, pero no olvidan sus costumbres y saberes locales, siguen conservando elementos identitarios, fortaleciéndose más como una cultura viva e incluso hay quienes han logrado un lugar en el mercado mundial de la oferta musical, como son las bandas musicales de la llamada corriente Etnorock. 
La música popular de los pueblos y la lengua originaria de los asentamientos son elementos de aporte a la identidad de un grupo étnico, ejemplos claros de lo mencionado son las costumbres que cada poblado practican de diferentes maneras, no obstante, pueden ser similares; y las lenguas originarias utilizadas o adaptadas en cada comunidad o municipio llevando a la creación de variantes gramaticales. Cabe señalar que la Organización de las Naciones Unidas para la Educación, la Ciencia y la Cultura (UNESCO) se ha dado a la tarea de reconocer el patrimonio cultural inmaterial y las tradiciones vivas (usos, representaciones, expresiones, conocimientos y técnicas ancestrales tradicionales relacionadas con la naturaleza y el universo y, las técnicas) de cada país que son únicas de su territorio y dan un sentimiento de identidad y continuidad, (UNESCO, 2003).

En la comunidad de Nuevo Carmen Tonapac se puede observar que se fortaleció un elemento identitario del grupo de músicos tradicionales; además del peso de la identidad cultural, tocan las melodías tradicionales propias de la localidad sin adaptarla a otros géneros musicales. Con base a lo descrito, las identidades que comparte los intérpretes de "Nuestra Señora del Carmen" no sólo es de pertenencia a un grupo de música tradicional; también es tener la afinidad de ser joven y poseer la habilidad de seguir reproduciendo los ritmos del carrizo y tambor.

\section{Masculinidades con Perspectiva de Género}

En México es muy reciente la inclusión de la Perspectiva de Género en las políticas públicas del Estado Mexicano, se fomenta la igualdad sustantiva de oportunidades entre mujeres y hombres y la necesidad de realizar acciones orientadas a evitar que se reproduzcan los roles y estereotipos de género para garantizar los derechos de las mujeres y evitar que las diferencias de género sean causa de desigualdad, exclusión o discriminación en cumplimiento con los compromisos firmados como la Convención sobre la Eliminación de todas las Formas de Discriminación contra la Mujer (CEDAW, por sus siglas en inglés) (Secretaría de Gobernación, 2016).
Es así que, en las políticas públicas como la política cultural, se ha considerado la Perspectiva de Género como temática transversal en los contenidos de sus programas, proyectos y acciones realizadas, en la que la participación de las mujeres es fundamental, ya sea en su papel de creadoras o de transmisoras de la cosmovisión, la lengua y la cultura propia (CONACULTA, s/a).

El sociólogo Michael Kimmel (1999), aboga por visibilizar desde el concepto de género la masculinidad, específicamente en lo que se refiere a la identidad, porque implica tener presente cómo se da la construcción de la masculinidad según la cultura, raza, clase, etnia, religión, sexualidad y edad, reconociendo lo que es común y variable.

En la construcción de la masculinidad tradicional es importante señalar que los varones "necesitan" actuar como violentos, bestiales, duros, atrevidos, agresivos. Han de estar permanentemente a la defensiva. Poseen en común, según Irving Goffman (s/a) cuatro reglas que tienen que cumplir siempre: "Nada de mariconadas"; "Sé importante"; "Sé duro como un roble" y, "Chingátelos" (citado por Kimmel, 1999).

Irma Cruz, María de Lourdes Hernández, Fernando Mino y Antonio Medina (2000), consideran este concepto de género en el sexo biológico masculino y mencionan que la conversión de un joven a varón es un transcurso que implica a su comunidad porque en la construcción de la masculinidad con los estereotipos de género establecidos por la sociedad se espera que "los hombres cumplan las reglas" para aprender, asimilar, rechazar conductas y roles.

En la definición de la masculinidad y de la pluralidad de masculinidades de cualquier clase social o edad, en donde hay que asegurar estereotipos de género en los que son "hombres" obedientes, disciplinados, y aprender a controlar sus emociones (autocastigo) y a expresarse con un lenguaje no incluyente (homófobo) como el de Hombre con mayúscula que cumple con su hombría y no cede a la coquetería “(...) incentiva en los hombres ciertos comportamientos como la competitividad, la demostración de virilidad, la búsqueda del riesgo y el uso de la violencia en determinadas circunstancias (REDIM, 2013, p. 139). 
La masculinidad hegemónica es una construcción que involucra una serie de prohibiciones de las que no se habla en las relaciones de los varones, no importa su edad, etnia, clase social, territorio, ambiente en que se desenvuelven; tienen que mostrar ante la sociedad, que "ser hombre" significa ser el mejor en lo que realiza, sin sentimientos, ser fuerte, violento; regirse y cumplir con los estereotipos que la gente señala para ser considerado un "verdadero hombre" con control total sobre la mujer y la descendencia familiar.

Una particularidad que tienen los grupos de música tradicional de los pueblos originarios, es que en su mayoría son varones, ejemplo de ello son los músicos zoques "Nuestra Señora del Carmen".

Cuando un grupo de jóvenes o varones mayores se juntan para llevar a cabo una actividad en común, como es el caso de estos intérpretes de música tradicional, se percibe que logran establecer una relación afectiva, rompiendo con los estereotipos de género dominantes que señalan a dichas actividades de acercamiento como expresiones construidas culturalmente como femeninas (abrazos, suaves palmadas, besos en las mejillas al saludarse o despedirse), o que necesitan ser violentos, agresivos para mostrar su virilidad.

Desde la fundación de la comunidad de Nuevo Carmen Tonapac, municipio Chiapa de Corzo, Chiapas, se sostiene que todos los artistas de música, y cabe mencionar los danzantes, han sido y son varones, no importa la edad, si son niños, jóvenes o mayores. Esta observación hace suponer que en las actividades culturales (canto, música, danza, entre otras) sólo participan varones, a quienes incluso se les permite interpretar a las mujeres anulando su presencia en dichas actividades.

La mujer por el peso del androcentrismo en esta composición de estereotipos de género se encuentra en notoria desvalorización y no se diga en la política, la industria, los negocios, incluso en las artes. Es relegada al ámbito privado (la casa, el trabajo doméstico) que implica la reproducción biológica y cuidadosocialización de la descendencia familiar, como algo propio y exclusivo a su condición de mujer. $\mathrm{Su}$ participación en lo público, bajo el patriarcado capitalista neoliberal es vista como algo "secundario".
Aunado al lenguaje sexista que opera en todos los ámbitos de nuestra sociedad, donde el mundo se expresa en "neutro" pero en masculino y omniabarcante, capaz de ocultar la desigualdad, pobreza y violencia que sufren las mujeres en el México y el mundo, pero en particular las mujeres de los pueblos originarios, que son las más excluidas de los servicios básicos, del ejercicio de sus derechos fundamentales $\mathrm{y}$ evidencian su escasa participación en la vida social, política, económica, jurídica y cultural del país.

Con la invisibilización de las mujeres como sujeta de investigación, y constructora del conocimiento a lo largo de la historia en México y en Chiapas de los sucesos de las comunidades y en la toma de decisiones de las esferas sociales, políticas y económicas, lo masculino figura como protagonista público y central de estos eventos, en los discursos y prácticas culturales.

Es aún grande el reto de adoptar la Perspectiva de Género como una cuestión de derechos humanos y de justicia social. No se afirma que la mujer es una víctima pasiva en permanente desventaja sometida en la esfera privada, pero sí se observa su aislada situación en los ámbitos públicos, culturales de la sociedad, y en esta investigación, la musical en particular.

\section{Metodología a desarrollar}

A través de las entrevistas, se preguntó por los conocimientos que han adquirido como músicos tradicionales y portadores de la cultura zoque proveniente del municipio de Chapultenango, Chiapas, debido a la erupción del Volcán Chichonal reubicada en municipio de Chiapa de Corzo; las razones del por qué formar un grupo con la música tradicional, sin combinar sus ritmos originales con otros géneros musicales como el rock (por el llamado Etnorock) o algún otro; sobre cómo aprendieron a tocar el tambor y carrizo (instrumentos tradicionales de Nuevo Carmen Tonapac); si han tenido alguna asesoría musical como pitero/tamborero de artistas locales; la existencia de notas especiales para el tambor o carrizo según particularidades de las festividades en las que ellos participan, o cuál es la forma de utilizar estos instrumentos musicales. De igual forma saber por qué los integrantes del grupo conocen y tocan las melodías tradicionales del municipio Chiapa de Corzo. 
Se elaboraron entrevistas estructuradas a los cuatro integrantes de "Nuestra Señora del Carmen", la guía tuvo un total de 23 preguntas, algunas de las preguntas fueron ¿Qué sienten ustedes de ser tamboreros? ¿Qué importancia juega la transmisión oral en la formación de los músicos tradicionales en Nuevo Carmen Tonapac? ¿Por qué son varones los tamboreros? ¿Qué significa para ti ser hombre? ¿La comunidad cómo describe a un hombre? ¿Qué opinas acerca de la mujer? ¿Cómo se construye una mujer dentro de la comunidad? ¿Les gustaría que hubiera mujeres tamboreras en el grupo? ¿La música anterior del Viejo Carmen es igual ahorita, o ha sufrido cambios? ¿Y la música tradicional de Chiapa de Corzo ha cambiado? Aunque cabe mencionar que dentro de estas mismas preguntas se realizaron otras más debido que a veces los actores no querían explayarse, ante esa situación se les hacían nuevas interrogantes relacionadas a lo que se quería saber con el fin de recaudar información.

También se hicieron preguntas desde la Perspectiva de Género, para identificar conductas sexistas de estos jóvenes, incluyendo la visión que ellos tienen hacia su sexo masculino y también hacia el sexo femenino, los estereotipos de la comunidad para la construcción identitaria de un hombre y una mujer, y si permitirían que las mujeres participaran dentro de su grupo musical.

Cabe mencionar que en ocasiones se da más importancia a los señores o a las personas mayores por la experiencia y sabiduría, decisión que se respeta porque han adquirido al paso de su vida conocimientos, aunque por usos y costumbres se sigue obviando que también la juventud, las mujeres y la niñez tienen derecho a participar en este tipo de actividades sociales, culturales y políticas.

\section{Resultados}

Norbert Dufourcq indica que "La música, (...), parece sinónimo de movimiento desde las épocas más remotas (...) La música vive de ritmo [éste] repetición de ruidos escandidos. Los primeros instrumentos de música fueron las manos" (2000, p. 11).
Los músicos utilizaron su cuerpo, para empezar a articular composiciones musicales, desde su existencia han sido los encargados de reproducir sonidos, melodías, asimismo crear composiciones musicales, sin ellos no se podría apreciar este arte, no habría música, ni la construcción de instrumentos musicales.

El carrizo y tambor, son instrumentos que muestran la estrecha relación de la música y la danza, representan cosmovisiones que se sustentan en la comunicación entre el Cielo y la Madre Tierra. En México, animan los eventos y consolidan la presencia de la afrodescendencia en los pueblos de América y el Caribe con ciertos grupos que evocan la música, los bailes y las danzas en las costas con descendencia de África.

Los intérpretes locales de Nuevo Carmen Tonapac, acompañados por los golpes del tambor y el liderazgo de las notas de la flauta de carrizo (ver Imagen 2), manifiestan identidad, hacen que las melodías de los rituales y ceremonias de la comunidad zoque expresen en conjunto un ambiente de alegría, símbolos, sentimientos, lenguajes, símbolos, evocaciones, exaltaciones hacia alguna deidad o creencia; es un arte que han conservado a través de los años a partir de la recuperación de la memoria oral y cultura musical zoque, coadyuvando a la recuperación de las melodías tradicionales que vienen de generación en generación familiar y de colectividad.

Cabe mencionar que estos instrumentos musicales han sido adaptados, producto del fenómeno migratorio al ser reubicados a otro territorio, este acontecimiento ocasionó que interactuaran y convivieran con, hasta ese entonces, la desconocida etnia Chiapa, donde se da un intercambio de usanzas e integrándose a las nuevas prácticas culturales como la "Fiesta Grande" de Chiapa de Corzo y respetando las diferencias musicales (Nandayapa, 2018); en consideración de Álvaro Villalobos Herrera esto suscita el sincretismo cultural (2006). 


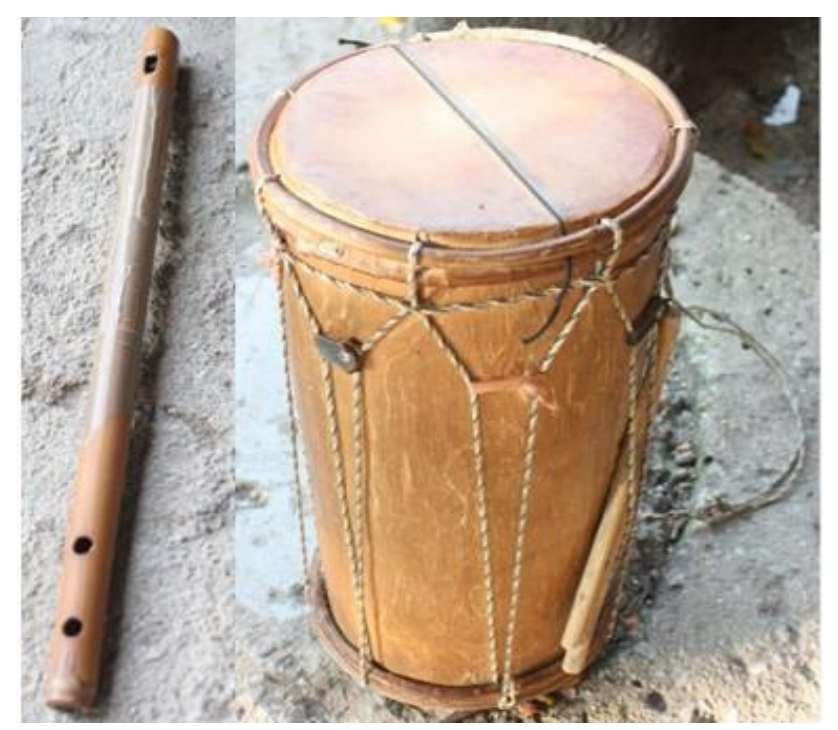

Figura 3 Instrumentos. (08 de noviembre 2018). Nuevo Carmen Tonapac, Chiapas. Foto y Edición digital: Maribel Hernández Núñez

"Nuestra Señora del Carmen" se formó en el año 2011, está conformado por cuatro jóvenes habitantes del lugar mencionado. Entre los cuatro músicos hay un carricero y tres tamboreros: Fermín Sánchez Gómez (uno de los dos fundadores, pitero, gracias a la herencia musical de su abuelo), Luis Adrián Díaz Méndez (tamborero), Francisco Javier Gómez Cordero (tamborero) y Teófilo Castro Gómez, (tamborero).

$\mathrm{Al}$ preguntarles a los cuatro integrantes se encontró que son varias las razones de por qué tocan la música tradicional zoque del carrizo (flauta) y tambor, entre ellas:

1. Contribuir a que no se acaben las tradiciones musicales de Nuevo Carmen Tonapac, municipio de Chiapa de Corzo, Chiapas.

2. Ayudar a preservar las melodías tradicionales que les heredaron sus antecesores zoques de Carmen Tonapac provenientes del municipio de Chapultenango, Chiapas.

3. Fortalecer desde temprana edad la presencia de los músicos tradicionales en Nuevo Carmen Tonapac, y motivar el interés de los jóvenes en continuar reproduciendo la música tradicional.

4. Si jóvenes o mayores no se interesan en aprender la música tradicional, el conocimiento musical se podría perder, debido a que los músicos (llamados popularmente en la comunidad, señores) van envejeciendo.
Al cuestionarlos por el valor que han adquirido los artistas locales en Nuevo Carmen Tonapac, ellos respondieron:

Francisco: "Es para dar realce a la comunidad, pues para no perder la tradición, seguir la costumbre de los antepasados" (2018).

Por su parte Luis Adrián dijo: "Es de mucha importancia, porque sin ellos no se podría hacer la fiesta" (2018).

A su vez, Teófilo señaló: "Para no perder la tradición y la costumbre, para que se alegre la fiesta" (2018).

Los jóvenes explicaron que sin la presencia de los músicos tradicionales no se consumarían las festividades, se suspenderían, porque son estos intérpretes locales los que proyectan alegría con las melodías a los habitantes, además de dar un esplendor a la comunidad, y ser quienes inician los novenarios (nueve días incluyendo el día principal donde se celebra la fiesta) en las solemnidades de las vírgenes o santos.

Los músicos relataron que pese a las creencias hacía los músicos tradicionales de que los jóvenes no deben ser tales, porque es relacionado con la brujería. La familia de los intérpretes no les parece agradable que ellos aprendan a tocar el carrizo o el tambor, en especial las madres. Sin embargo, desde la niñez al escuchar los ritmos del tambor y de la flauta empezaron a mostrar interés por manipular estos instrumentos de la comunidad.

Para adentrarse al conocimiento musical se relacionaron con los músicos mayores quienes sólo les recomendaban que escucharan las melodías y aprendieran mirando la manera en que debían de ejecutar dichos instrumentos, "(...) te van dando poquito a poquito los tambores para que empieces a tocar" (Francisco, 2018). Con lo descrito los aprendices de la cultura musical tienen que ser muy hábiles para mirar, escuchar y entender los ritmos del carrizo y del tambor, dependiendo de lo que desean tocar; el pitero debe saber las composiciones de las melodías del carrizo, para ser la guía de los tamboreros, porque el pitero indica los cambios de los ritmos, y los tamboreros deben percatarse del sonido del carrizo para saber en qué momento cambiar la sinfonía. 
"Nuestra Señora del Carmen" declaró que las notas musicales del carrizo y tambor provienen de las melodías "Credo", "Alabanzas", "Procesión"; por lo que la armonía del carrizo es fundamental para que los tamboreros sigan la música, y conozcan las diferencias en las melodías que interpretan en cada una de las festividades de la comunidad, por ejemplo los cantos denominados "Procesión" y "Credo", son caracterizados por la dificultad que tienen al tocarlas; la melodía de "Procesión" inicia lento y después se vuelve rápido conforme avanza la melodía; el "Credo" es un canto complejo que comienza rápido, pero según avanza la música se vuelve lento, debido a estos cambios rítmicos es que los músicos han de permanecer atentos y escuchar en el carrizo los cambios de tonos. Describieron que cada canto tiene un significado dedicado a las vírgenes o los santos.

Los artistas juveniles expresaron que la música ejecutada por ellos son composiciones lentas y cortas, diferentes a las interpretaciones de los músicos de Carmen Tonapac, municipio de Chapultenango; opinaron que las canciones son "suaves", "más largas" y, "las danzas las bailan con más cultura, más estilo".

Los jóvenes músicos afirmaron que debido a la reubicación y el alejarse de su municipio original, las costumbres musicales como son los ritmos del carrizo y tambor, sí tuvieron cambios; por lo que las melodías tradicionales de Nuevo Carmen Tonapac son únicas de ese asentamiento, debido a que no comparten las sinfonías con otra localidad zoque.

Una característica es que los artistas locales son de religión católica, asimismo los participantes de la Junta de Festejos y la población que acude a dichas celebraciones. Asimismo, nombran a uno o más representantes conocidos por la cosmovisión zoque como alférez, éstos se encargan de elaborar las velas que servirán para la fiesta de la virgen o del santo.

Las seis danzas que se llevan a cabo en Nuevo Carmen Tonapac son "La Danza del Caballito", "La Danza de La siembra", "La Danza de Actitan", "La Danza del Tigre”, "La Danza de La Niña", "La Danza de Santiago de Galicia”.
Uno de los eventos que simbolizan unión entre los habitantes zoques son "Las Enramas" (ver Imagen 3), troncos de aproximadamente 2 metros al que les cuelgan objetos como cubetas, frutas, panes, etc., esta actividad se comienza desde los hogares de las personas donde las realizan, las cargan en los hombros, y caminan con todos los presentes, incluyendo a los músicos tradicionales quienes van ejecutando el carrizo y el tambor, hasta llegar al recinto religioso; al término del viaje la gente dona los artículos colgados de la enrama a los encargados del templo para que al día siguiente los vendan y recaudan fondos a beneficio del santuario. Al inicio de la caminata los dueños de las casas que hacen las enramas ofrecen alimentos o bebidas a sus invitados.

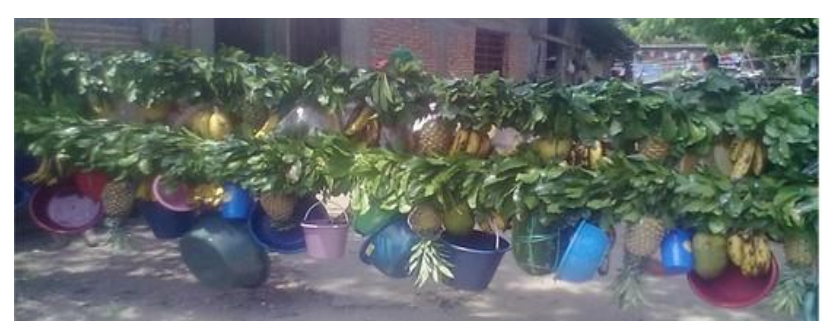

Figura 3 Enrama. (08 de noviembre 2015). Nuevo Carmen Tonapac, Chiapas

Foto: Maribel Hernández Núñez.

Los entrevistados declararon que en un principio cuando empezaron a participar como músicos tradicionales en las fiestas, rituales o ceremonias, al dormir tenían pesadillas. Estos jóvenes explicaron que las pesadillas son "pruebas" que ellos deben pasar, hechos por los músicos mayores para probar si de verdad son dignos de ser músicos zoques, y esa situación les ha ocasionado disgusto; por lo que esas llamadas "pruebas" han generado conflictos con los dos grupos de músicos que existen en la comunidad.

Los cuatro músicos expresaron que han sufrido pesadillas, causándoles un sentimiento de espanto, pero no les gusta mencionarlas porque son experiencias íntimas que sólo comentan entre ellos; él único que quiso revelar un poco de lo que le hacen mientras duerme fue Francisco, quien tímidamente narró que en sus sueños se presentan personas que "le hacen maldades", como "quemaduras en el cuerpo". Otra razón fuerte para abandonar las prácticas tradicionales son las religiones protestantes, dichas corrientes no conciben estas costumbres y sólo creen en una deidad o ser espiritual que rige la vida de todo lo que exista en el planeta Tierra o universo. 
Éstas no permiten que los seguidores se involucren en las tradiciones de la comunidad, debido a que las actividades culturales están fuertemente ligadas a las creencias zoques y al catolicismo, ante esta situación se han alejado de sus costumbres zoques.

A pesar de lo expuesto, ninguno de los conflictos entre ambos grupos de artistas, mayores y jóvenes, han sido motivos para que se alejen de interpretar la música tradicional de la comunidad, sino por el contario, se han preocupado por seguirla reproduciendo.

\section{"Ser músico es cuestión de hombres"}

Históricamente, la figura del varón ha sido la protagonista de los eventos más importantes y de carácter público. El grupo juvenil explicó que a lo largo de la historia de esta comunidad siempre han sido hombres los que participan como músico o danzante, los ancianos determinaron que sólo serían varones los artistas de este asentamiento, y nunca permitieron que las mujeres interpretaran las melodías tradicionales o participaran en las danzas, debido a lo peligroso que era por su condición de sexo y a que las mujeres tenían miedo sobre la creencia de la brujería.

Al preguntarles a los integrantes del grupo juvenil los significados que tienen para ellos ser varón, así contestaron:

Fermín expuso: "Significa ser sobrevalorado más que una mujer y respetado" (2018), Francisco expresó: "El valor que tiene uno y demostrarlo, una aportación en la colonia y las tradiciones" (2018), se refiere a que él por ser un joven tiene la libertad de participar en los eventos de la comunidad como músico o danzante sin que los habitantes lo critiquen por su género.

Luis Adrián describió: "Pues para mí significa mucho" (2018), él expresó que por su condición de ser hombre puede hacer las actividades que le gusta sin tener una limitación o miedo, en especial ser músico.

Teófilo: comentó "Usar ropa de hombre" (2018), esta expresión señala que los varones deben de arreglarse con camisas o pantalones, sino se visten así serían criticados por los habitantes de este lugar.
Las opiniones acerca del significado que tiene para ellos ser varón (hombre) involucra una concepción de tener más privilegios que las mujeres: entre ellos la libertad; están menos expuestos a que los critique la sociedad, y deben utilizar accesorios de hombres para ser visto como tales.

También se les preguntó cómo considera la comunidad el término varón (hombre), y respondieron que una característica que tienen los habitantes de Tonapac con este concepto es la fuerza, debido a que los varones se dedican a realizar trabajos donde se maneje un grado de desgaste como podría ser cargar leña o levantar objetos pesados, trabajar como agricultor en el campo, etc. Debido a estos patrones culturales los varones creen que son trabajos ideales para ellos.

Después de presentar las opiniones de "Nuestra Señora del Carmen" sobre la concepción de varón en la comunidad, fue importante conocer la opinión de ellos y la comunidad en general acerca de la figura de la mujer.

Fermín comentó que en su hogar su padre y madre le enseñaron a respetar a las mujeres, sin creerse más que ellas por su condición de hombre, mencionó que sería importante la intervención de las mujeres en las actividades culturales de la comunidad como músico o danzante.

Luis Adrián expresó: "Para mí la mujer es un ser bueno, porque sin ellas no seríamos nada los hombres" (2018), él idealiza a la mujer como una persona sensible, además destaca la presencia de una fémina en su vida, pero agregó que también la cataloga como un elemento para la reproducción de los seres humanos.

Francisco explicó que hombres y mujeres hacen el mismo trabajo en cuanto a la cantidad de actividades, pero dividiendo los roles de género de cada persona; señaló que los hombres son los encargados de trabajar en el campo de agricultor para proveer a su familia, y la mujer haciendo labores domésticas como la preparación de alimentos, mantener en orden su casa, cuidar a los hijos, etc. Teófilo describió que las mujeres "son delicadas, sensibles", poniéndolas como personas de carácter tierno, de emociones sentimentales, tal y como está en el imaginario colectivo de la cultura mexicana. 
En general representan a la mujer como personas tranquilas, afectivas, comprensibles, que se encargan de realizar actividades para cuidar un hogar, es decir, los roles sociales que el sistema patriarcal ha "normalizado".

Los cuatro jóvenes del grupo comentaron que actualmente en Nuevo Carmen Tonapac existen dos opiniones hacia la mujer por parte de las personas de la tercera edad (provenientes de Carmen Tonapac) y los señores; la gente mayor insta a las jóvenes que están solteras, permanezcan en su casa; no están de acuerdo que salgan si no tienen ninguna razón o actividad para hacerlo, además de pasear en la comunidad de noche, no les parece que anden en horas nocturnas y les aconsejan que se vayan a su hogar a descansar; además piden a las jóvenes solteras se vistan con el traje tradicional zoque, y los padres elijan con quién se casará la joven a una edad adulta; estas ideas de la mujer que tienen las personas de la tercera edad es sobre los hábitos que han vivido.

Para los señores que tienen hijas, explicaron que ya les dan un poco de "libertad" debido a que las dejan salir por el día, los padres de familia no se molestan que ellas anden fuera de su casa, pero también les prohíben que las jóvenes estén de noche en la comunidad; agregaron que ahora las jóvenes deciden con quién se casan.

Fermín opinó que no le parecen justas las prohibiciones que tienen las mujeres en la comunidad, porque mujeres y hombres deben de tener la misma igualdad y libertad para realizar las actividades que decidan hacer.

Luis Adrián contó que en las asambleas o juntas que se realizan en Tonapac, las mujeres tienen participación y su opinión es tomada en cuenta. Cabe destacar que el grupo juvenil "Nuestra Señora del Carmen" está de acuerdo que las mujeres se integren a las actividades culturales de la comunidad como podría ser la música o la danza, debido a que han visto interés de ellas por aprender las prácticas que los hacen identificarse como zoques. A ellos les gustaría que hubiera mujeres que tocaran la música del carrizo y del tambor, asimismo expresaron que están dispuestos a enseñarles a las interesadas las melodías de los instrumentos tradicionales.
Ante la iniciativa que tienen sobre la incursión de las mujeres en interpretar los ritmos tradicionales, para los señores del asentamiento no es una idea adecuada; Fermín, comentó que una prima se le acercó a consultarle si se podría integrar con ellos para aprender y tocar en un futuro las melodías tradicionales, él contestó que sí, pero la joven al comentarle a su papá la decisión que había tomado, su padre dijo que no le parecía y que "ser músico es cuestión de hombres", ante esta negativa la chica prefirió no unirse.

Con la respuesta que le explicó su prima, Fermín enunció que no está de acuerdo con la opinión de su familiar, debido a que él piensa que las mujeres deberían de participar como artistas tradicionales.

En la actualidad, la comunidad de Nuevo Carmen Tonapac todavía conserva prácticas donde a la mujer no se le ha permitido tener total libertad, pero en algunos aspectos puede participar y opinar.

\section{Agradecimiento}

A la Universidad Intercultural de Chiapas (UNICH) por facilitar la participación en el Congreso.

\section{Conclusiones}

1. A través de los músicos tradicionales zoques se ha analizado desde la comunicación intercultural, los estudios de género, y la masculinidad, la importancia de salvaguardar los ritmos del carrizo y del tambor en Nuevo Carmen Tonapac.

2. En cada comunidad, estado, país, continente, la identidad da cuenta de la cultura, tradición, expresiones artísticas, y que no hay una cultura mejor que otra. Todas las identidades culturales son dignas e importantes, y es precisamente por estas representaciones en donde la comunicación intercultural tiene un papel significativo, porque se aprende a generar un diálogo multicultural e intercambio de saberes y conocimientos con los demás grupos sociales. Por ejemplo, las expresiones musicales a través del sonido del tambor y el carrizo. 
3. Al decidir conformar un grupo de música tradicional, entre adolescentes, marcaron una primera distancia entre la música tradicional ejecutada por los adultos mayores de la comunidad, y ellos, que buscaron desde un principio tener una identidad propia pero guardando símbolos y tradiciones de la cosmovisión zoque con la localidad de origen donde provenían los antiguos intérpretes; cada grupo de músicos tradicionales de los dos asentamientos zoques interpretan el ritmo del carrizo y tambor a su manera.

4. Es admirable, saber que la música tradicional existente en Nuevo Carmen Tonapac es única, cuyos expositores interpretan melodías exclusivas de este asentamiento.

5. Fermín, Luis Adrián, Francisco y Teófilo afirmaron que sí les gustaría ver la participación de mujeres como portadoras de los ritmos tradicionales zoques dentro del grupo, debido a que han percibido el interés de las mujeres por querer aprender la música tradicional, por lo que estarían dispuestos a enseñarles a ellas las melodías locales, pero éstas no se deciden por el miedo a las creencias que existen y las consecuencias que atravesarían según ellas, si se atreven a convertirse en músicos.

6. La comunidad de Nuevo Carmen Tonapac no concibe la idea de la incursión del sexo femenino en actividades que no sean "propias de las mujeres" y que impliquen pasar horas fuera de casa, aparte de que "no es natural" que ellas incursionen en los ámbitos exclusivos de los varones a través de cantos en los rituales públicos, procesiones, alabanzas, rezos, o de curanderas.

7. Es triste que, por los mitos de la mexicanidad, las ideas de negación de nuestras propias raíces y por los prejuicios religiosos, la sociedad considere que preservar los elementos culturales de Mesoamérica, es algo arcaico, "pasado de moda".
8. Entre más personas se involucren en seguir aprendiendo las actividades formativas como lo son la danza y la música de nuestros pueblos originarios de México, más posibilidad habrá de asumir la responsabilidad por el respeto ante la diversidad, la herencia cultural, la identidad cultural, y la pluralidad cultural en el escenario de la globalización neoliberal.

9. Las prácticas colectivas existentes de los pueblos originarios permiten conocer diversas expresiones culturales y lograr un propósito en común: seguir conservando y divulgar la identidad cultural.

\section{Referencias}

Alsina, M. R. (2011). ¿Qué es la comunicación intercultural? En La comunicación intercultural. Recuperado de https://bit.ly/2ki6iiE

Castro Gómez, T. (2018). Comunicación Personal [Entrevista]. 15 de marzo. Nuevo Carmen Tonapac, Chiapas.

Consejo Nacional para la Cultura y las Artes (CONACULTA). (s/a). Reporte global sobre equidad de género y cultura del Consejo nacional para la cultura y las artes. Recuperado de https://bit.ly/2lU7U2z

Cordero, M. (22 de febrero de 2006). Exclusiones que afectan a las mujeres indígenas. Históricamente, las mujeres indígenas han estado marcadas por la exclusión de la sociedad, y ha provocado el fenómeno de su invisibilización. Recuperado de https://bit.ly/21Qm3xV

Cruz, I. et al. (6 de abril de 2000). ¿Cómo se hace un hombre? La Jornada. Letra S. Recuperado de https://bit.ly/21U87Tp

Díaz Méndez, L. A. (2018). Comunicación Personal [Entrevista]. 15 de marzo. Nuevo Carmen Tonapac, Chiapas. 
Dufourcq, N. (2000). Breve Historia de la Música. México: Fondo de Cultura Económica. Espinosa, M. M. y Gilyam, M. G. (2012). Sincretismo Cultural Mestizaje cultural en México y Perú. Recuperado de http://bdigital.uncu.edu.ar/objetos_digitales/464 0/trabajocatedra.pdf

Giménez, G. (s/a). La investigación cultural en México, una aproximación. Recuperado de https://bit.ly/2lWpkfa

Glosario de términos sobre género y derechos humanos. (s/a). Recuperado de https://bit.ly/1PyMqLH

Gómez Cordero, F. J. (2018). Comunicación Personal [Entrevista]. 15 de marzo. Nuevo Carmen Tonapac, Chiapas.

Gómez Vargas, H. (s/a). Los Estudios Culturales y los Estudios de la Comunicación. Las membranas del tiempo y del espacio en la era de la comunicación digital. Recuperado de https://bit.ly/2aGpmPC

Google. (s.f.). Mapa de Chiapa de Corzo, Chiapas, Chiapa de Corzo en Google maps. Recuperado de https://bit.ly/2koxYma

Grossberg, L. (2003). Capítulo 6, Identidad y estudios culturales: ¿No hay más que eso? En Guevara Ruiseñor, E. S. (2008). La masculinidad desde una perspectiva sociológica. Una dimensión del orden de género. Recuperado de https://bit.ly/1TY8r7Q

Hall, S. y Du Gay, P. (2011). (Compil.). Cuestiones de identidad cultural. $1^{\text {a }}$ edición. Buenos Aires-Madrid: Amorrortu editores. Herrera Gómez, C. (28 de marzo de 2015). La crisis de masculinidad y los Nuevos Hombres. Recuperado de https://bit.ly/2lTshwZ

Huéhuetl mexica. (s/f). Recuperado de https://bit.ly/2lWVMOc

Instituto Nacional de Estadística y Geografía (INEGI). (2010). Censo de Población y Vivienda 2010. Recuperado de https://bit.ly/2Qok39L
Instituto Nacional para el Federalismo y el Desarrollo Municipal (INAFED). (2000). Enciclopedia de los Municipios y Delegaciones de México. Estado de Chiapas, Chiapa de Corzo. Recuperado de https://bit.ly/2n5hEHj Kaufman, M. (6 de abril de 2000). Masculinidad dominante, armadura que paraliza. La Jornada. Letra S. Recuperado de https://bit.ly/2oIyc63

Kimmel, M. (8 de abril de 1999). La masculinidad y la reticencia al cambio. $L a$ Jornada, Letra S. Recuperado de https://bit.ly/2kE4LDZ

Martínez Lirola, M. (2011). Notas sobre la visibilidad y la invisibilidad de las mujeres en nuestra sociedad: el caso concreto de la Universidad de Alicante. Revista Nuevas Tendencias en Antropología, (2). Recuperado de https://bit.ly/21WpMKo

Mattelart, A. y Neveu, É. (2004). Introducción a los estudios culturales. Barcelona: Paidós. Recuperado de https://bit.ly/2lTk9MO

McEntee, E. (1998). Capítulo 4. La comunicación intercultural. En Bases para la comunicación efectiva en el mundo actual. México: Mc Graw Hill.

Morales, D. (7 de agosto de 2015). Las tradiciones mexicanas más valiosas. Recuperado de https://bit.ly/2m7T9na

Moreno Rivas, Y. (1989). Capítulo 3. El alma viviente de la música mexicana: música regional de siempre. En Historia de la Música Popular Mexicana. México: Alianza Editorial Mexicana. Nandayapa, M. (2018). Comunicación Personal [Entrevista]. 19 de junio. Chiapa de Corzo, Chiapas.

Navarrete, S. (2005). Los significados de la música: La marimba maya achí de Guatemala. México: Casa Chata. CIESAS.

Nettl, B. (1992). Capítulo 5. Últimas tendencias en etnomusicología. Recuperado de https://bit.ly/2kkjRhH 
Nuevo Carmen Tonapac. (s/a). Elaboración propia. Recuperado de https://bit.ly/2kPIzXt https://bit.ly/2mdeK3h https://bit.ly/2mks0mV Oliva, A. (13 de septiembre 2000). La etnomusicología hoy, en Introducción a la etnomusicología. Recuperado de https://bit.ly/21X5zUq

Organización de las Naciones Unidas para la Educación, la Ciencia y la Cultura (UNESCO). (s/a). Los ámbitos del inmaterial patrimonio cultural. Recuperado de https://bit.ly/1K9AAYi Paul, C. (2005). Reúne la Feria Internacional del Libro Universitario a más de 400 editoriales. $L a$ Jornada. Recuperado de https://bit.ly/2ki5Y3q

Red por los Derechos de la Infancia en México. (REDIM). (2013). La desigualdad de género comienza en la infancia: Manual teóricometodológico para transversalizar la Perspectiva de Género en la programación con enfoque sobre derechos de la infancia. México: Secretaría de Desarrollo Social. Recuperado de https://bit.ly/2kjsNnl

Reyes, M. A. (5 de enero de 2012). La salvaguarda de la hombría, el machismo dentro del Ejército. La Jornada, Letra S. Recuperado de https://bit.ly/2kPID9F

Reynoso, C. (2000). Capítulo 1: Definiciones: ¿Qué son o qué han llegado a ser los estudios culturales en la actualidad? En Apogeo y decadencia de los estudios culturales: Una visión antropológica. Barcelona: Gedisa.

Samaniego Sastre, M. (2005). Capítulo. Interculturalidad como dimensión inherente a la comunicación humana. En Condiciones y posibilidades de las relaciones interculturales: un proceso incierto. Serie: Dinámicas Interculturales, (5). Barcelona: CIDOB edicions. Sánchez Gómez, F. (2018). Comunicación Personal [Entrevista]. 15 de marzo. Nuevo Carmen Tonapac, Chiapas.

Santiago, T. (2014). Masculinidad tradicional: estereotipos y publicidad. Recuperado de https://bit.ly/1noI4te
Secretaría de Gobernación. (2016). Examen de los informes presentados por los Estados partes en virtud del artículo 18 de la Convención sobre la eliminación de todas las formas de discriminación contra la Mujer: Noveno informe periódico que los Estados partes debían presenter. Recuperado de https://bit.ly/2MW521O

Szurmuk, M. y Mckee Irwin, R. (Coords.). (2009). Diccionario de Estudios Culturales Latinoamericanos. México, Siglo XXI Editores: Mora.

Tipa, J. (2014). Rock en tu idioma, rock en mi idioma: etnicidad y geografías culturales en el consumo del rock en tsotsil. En Cruz López Moya, M. de la, et al. (Coords.). Etnorock, los rostros de una música global en el sur de México. México: Imprenta Juan Pablos editor.

Tranchefort, F. R. (2004). Los instrumentos musicales en el mundo. Madrid: Alianza Editorial.

Villalobos Herrera, A. (2006). El Sincretismo y el Arte Contemporáneo Latinoamericano. Revista Ra Ximhai. 2 (2). México: Universidad Autónoma Indígena de México. Mochicahui, El Fuerte, Sinaloa. Recuperado de https://bit.ly/2kjugdl

ViveMx. (2014). Chiapa de Corzo, Chiapas. Recuperado de https://bit.ly/2m1qVjw

Volcán Chichonal. (s/f). Recuperado de https://bit.ly/2kpdQQU 